\title{
Studies on Structure and Elasto-Mechanical Properties of Suvin Cotton Fibre
}

\author{
V. V. Manju ${ }^{1 *}$, S. Divakara ${ }^{1}$, R. Somashekar ${ }^{2,3}$ \\ ${ }^{1}$ Vidyavardhaka College of Engineering, Gokulam, 3rd Stage, Mysuru and affiliated to \\ Visvesvaraya Technological University, Belagavi, Karnataka, India \\ ${ }^{2}$ Center for Material science, University of Mysore, Vijnana Bhavan, Mysuru, Karnataka, India \\ ${ }^{3}$ Department of Physics, Regional College of Education, Mysuru, Karnataka, India
}

Received 28 May 2020, accepted in final revised form 1 July 2020

\begin{abstract}
The comprehensive elastic properties of Suvin cotton fibre have been estimated. The Linked Atom Least Square method (LALS) technique has been employed to compute the structural properties using the X-ray diffraction data. Using Treloar's assumptions the elastic stiffness matrix $|\mathrm{Cij}|$ has been calculated, then by utilizing the Voigt theory the elastic constants like Young's modulus (E), Bulk modulus $(\mathrm{K})$, Shear modulus $(\mathrm{G})$, Poisson's ratio $(v)$ and linear compressibility $(\beta)$ have been estimated. Further, the experimental results of elastic constants are obtained and compared with the computed results and a broad correlation between them has been observed. ELATE web application tool is used to obtain the 3dimensional images of variation of elastic constants along their spatial axes. From these figures an attempt has been made to explain the anisotropic mechanical property with respect to directional dependent Young's modulus (E) and Shear modulus properties (G).
\end{abstract}

Keywords: Elastic constants; WAXS; LALS; ELATE; Cotton fibre; Suvin cotton.

() 2020 JSR Publications. ISSN: 2070-0237 (Print); 2070-0245 (Online). All rights reserved. doi: http://dx.doi.org/10.3329/jsr.v12i4.47269 J. Sci. Res. 12 (4), 607-620 (2020)

\section{Introduction}

Cotton fibres are fascinating because of their many positive advantages and are extensively used in the textile industry for more than 3000 years and are the third most widely produced agricultural and industrial crop [1-3]. Among natural fibres, cotton is the top chosen fibre due to its fibre strength, comfort, and ability to absorb moisture [4]. It is naturally $90 \%$ of cellulose, hydrophilic in nature and belongs to the Gossypium family. Its chemical formula is $\left(\mathrm{C}_{6} \mathrm{H}_{10} \mathrm{O}_{5}\right)_{\mathrm{n}}$, a polysaccharide encompassing of a linear chain of many $\beta(1-4)$ linked D-glucose units. Cellulose is a polymer of a macromolecule built by a long chain of glucose molecules linked with $\mathrm{C}-1$ to $\mathrm{C}-4$ oxygen bridges. The anhydroglucose units are linked together as $\beta$-cellobiose. The degree of polymerization (DP) is the numerical count of repeating units attached together to make the polymer of

${ }^{*}$ Corresponding author: manjuvv@vvce.ac.in 
cellulose, which is approximately 2076 for Suvin cotton fibre [3]. Cotton is made up of multi-layered structure, primary wall, secondary wall, and lumen. The outer surface has a major impact on the fibre properties. Many researchers around the globe are working on the study of basic properties and also the structural modifications of cotton fibre to attain more stability by depositing nano-composites on the cotton fibre [4-10]. The elastic properties of cotton fibre play an important role in the textile industry applications. These elastic properties measure the material resistance to being deformed elastically when stress is applied and also defines the lifetime of the product. The accepted best practice to study the elastic properties of any material is, by analysing the basic elastic constants such as Young's modulus (E), Shear modulus (G), Bulk modulus (K), Poisson's ratio (v) and linear compressibility $(\beta)$. These moduli can be defined within the elastic limit of a material. The measure of solid's stiffness or resistance to elastic deformation under load is Young's modulus (E), it relates stress to strain along an axis or line which is directional dependent and it is the ratio of longitudinal stress to longitudinal strain. Shear or rigidity modulus $(G)$ is a numerical constant that characterizes the elastic property of a solid under the application of transverse internal forces and it is the ratio of tangential stress to shearing strain. Bulk modulus (K) describes how resistance a substance is to compression and it is the ratio of compressive stress to volume strain. Poisson's ratio (v) determines the deformation of the body perpendicular to the applied force direction and it is the ratio of lateral strain to longitudinal strain. The linear compressibility $(\beta)$ depicts the relative rate of its linear dimensions with respect to pressure. In the present investigation, an attempt has been made to determine the structure-property relations for Suvin cotton fibre. The dependence of bulk properties of cotton on its structure is discussed using X-ray diffraction studies and a set of mathematical programs. The LALS program which is developed in the Linux platform has been used along with the molecular model, standard bond length, and bond angle to determine the crystal structure of the Suvin cotton fibre. PLATON [11] software has been used to project a polymer chain in the unit cell along different axes. Also, this research seeks to capture the physical, structural, and the elastic properties and their dependence on the anisotropy of the material. Experimentally the cotton fibre is semi-crystalline material and shows crystallinity of different degrees, though X-ray diffraction displays sharp peaks $[12,13]$. The shape of the ordered region in different Bragg reflections has been computed in our previous study [14].

The main objectives of this study are,

- To report the crystal structure of Suvin cotton fibre using the LALS program.

- To obtain the elastic constants using 6×6 symmetric matrix and ELATE web application tool and to plot 3-dimensional images of variation of elastic moduli like Young's (E), Bulk (K), Shear (G), Poisson's ratio (v), Linear compressibility $(\beta)$ for the Suvin cotton fibre.

- To compare the elastic moduli of theoretical values with the experimental results. 


\section{Materials and Methods}

\subsection{Collection of samples}

For this investigation, the lint of raw Suvin cotton fibre is used without any supplementary treatments, this fibre is procured from the Agricultural University, Shivamogga, India, after the ginning process. Ginning is a procedure, where the raw cotton is detached from the seeds, seed hulls, and other items. Ginning should be completed prior to other experimental investigation of cotton fibre.

\subsection{X-ray diffraction studies}

For XRD studies, a small bundle of the sample is mounted to the sample holder. The sample holder is mounted on the goniometer so that the rotational axis was parallel and perpendicular to the fibre axis and X-ray beam respectively. The XRD pattern for Suvin cotton fibre is recorded using Digital Imaging Plate (DIP-3200) with $440 \times 240 \mathrm{~mm}^{2}$ dimensions and moved corresponding to the pivot of turn. The used X-ray beam wavelength was $0.71073 \AA$ (Mo target). The settings of the X-ray generator (RIGAKU) were $32 \mathrm{~mA}$ and $50 \mathrm{kV}$. The time of exposure was kept for $400 \mathrm{~s}$. The Weissenberg geometry [15] image of Suvin cotton fibre is given in Fig. 1. The MOSFM software which is supplied with the instrument is used to carry out the scanning of $2 \theta$ versus intensity.

\section{Suvin}

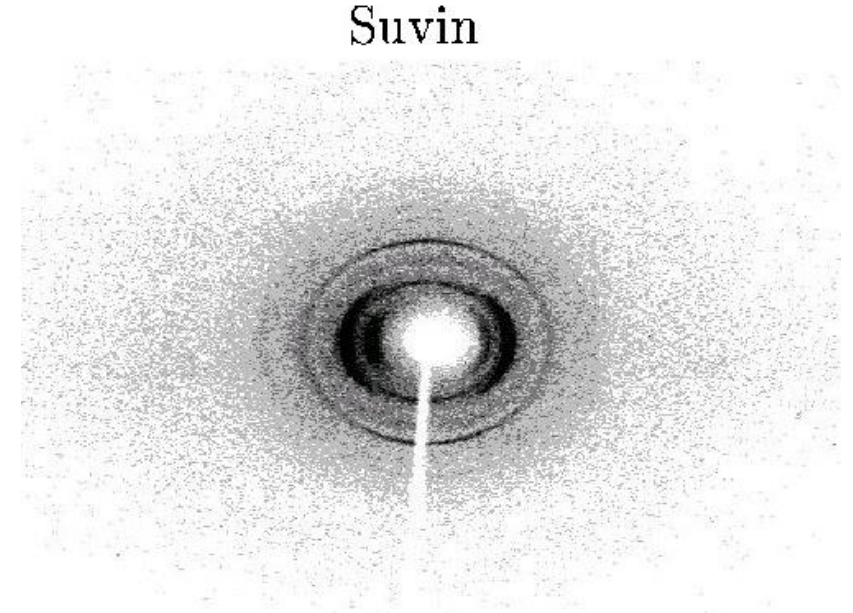

Fig. 1. The pattern of X-ray diffraction (imaging plate) recorded for Suvin cotton fibre.

\subsection{X-ray diffraction data}

Using XRD data and Peakfit ${ }^{\circledR}$ software [16], 10 Bragg reflections are identified. The cell parameters are calculated by employing these Bragg reflections along with a program Checkcell [17]. The studied cotton fibre cell parameters are $\gamma=96.28^{\circ}$ and $\mathrm{a}=7.350 \AA, \mathrm{b}$ 
$=8.220 \AA, \mathrm{c}=10.370 \AA$ with monoclinic and space group $\mathrm{P} 2_{1}$ [17]. FWHM for each Bragg reflection has taken from Peakfit ${ }^{\circledR}$ program. The computed microstructural parameters are shown in Table 1.

Table 1. Microstructural parameters of Suvin cotton fibre.

\begin{tabular}{llll}
\hline $2 \theta(\mathrm{deg})$ & Intensity (a.u) & (hkl) & $\mathrm{d}(\AA)$ \\
\hline 5.21 & 187.86 & 100 & 8.02 \\
7.52 & 349.71 & -110 & 5.56 \\
8.12 & 875.72 & -111 & 5.15 \\
11.23 & 1786.10 & 200 & 3.72 \\
13.07 & 81.49 & -202 & 3.20 \\
14.47 & 314.20 & 113 & 2.89 \\
15.44 & 89.01 & 031 & 2.71 \\
16.99 & 325.38 & -114 & 2.46 \\
19.73 & 189.43 & -232 & 2.12 \\
23.05 & 150.01 & -241 & 1.82 \\
\hline
\end{tabular}

\subsection{Mechanical properties}

The strength of the cotton fibre contributes substantially to the quality of the cotton. The experimental mechanical properties such as tenacity and elongation of Suvin cotton are carried out in Central Silk Technological Research Institute, Central Silk Board, Bangalore, India using Fibre Bundle Strength Test, with a method IS:3675-1996 in the Instron Instrument at temperature $27^{\circ} \mathrm{C}$. For test made at a finite Gauge length of 3.175 $\mathrm{mm}(1 / 8 \mathrm{inch}), \mathrm{n}=5$, the bundle length of $15 \mathrm{~mm}$ and the width is $6 \mathrm{~mm}$ approximately $[18,19]$. In this test, the bundles of fibres may be secured by clamps are either in close contact (zero-gauge length) or by clamps separated to give a finite gauge length. Investigations indicate that a finite Gauge length of $3.175 \mathrm{~mm}(1 / 8 \mathrm{inch})$ may be more closely related to the tenacity of many classes of cotton yarn $[18,19]$.

\section{Determination of Structural and Elastic Properties}

\subsection{Linked Atom Least Squares (LALS) program}

The LALS mathematical program was initially written using Algol by Wonacott and this version subsequently expanded and translated to Fortran by Dover, Hukins, Scott, and Chandrasekaran. The IBM compatible version was developed in the year 1977 by P. Smith at Purdue [20]. The main goal of this scientific program is to perform the refinement of molecular structures and to obtain the model of atomic structures using some crystallographic tools like PLATON along with LALS. Employing this technique, it is presently conceivable to make a precise atomic model in a unit cell by contributing the mandatory parameters of this sub-atomic structure into the program. For the procedures and methods, we referred to our earlier article [1], the obtained molecular model of Suvin cotton fibre is shown in Fig. 2 and the packing structure along a, b, and c axis are as shown in Fig. 3. The obtained fractional atomic coordinates, final model parameters after several refinements are shown in Tables 2 and 3. 


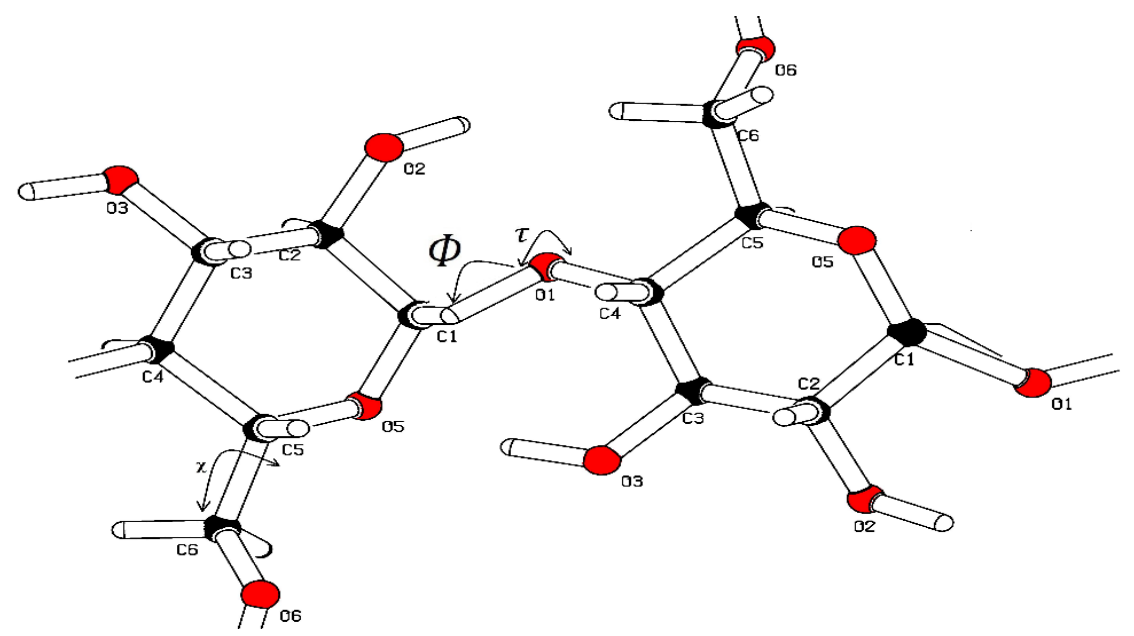

Fig. 2. The molecular model of Suvin cotton fibre, (a) black ball is the carbon atom and grey ball is the oxygen, (b) $[\varphi(\mathrm{C} 2-\mathrm{C} 1-\mathrm{O} 1-\mathrm{C} 4), \psi(\mathrm{C} 1-\mathrm{O} 1-\mathrm{C} 4-\mathrm{C} 3)$ and $\chi(\mathrm{O} 5-\mathrm{C} 5-\mathrm{C} 6-\mathrm{O} 6)$ are the torsion angles $]$ and (c) $[\tau(\mathrm{C} 1-\mathrm{O} 1-\mathrm{C} 4)$ is the glycosidic angle $]$.

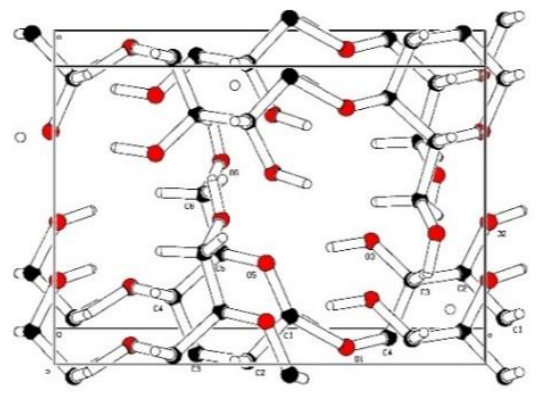

(a)

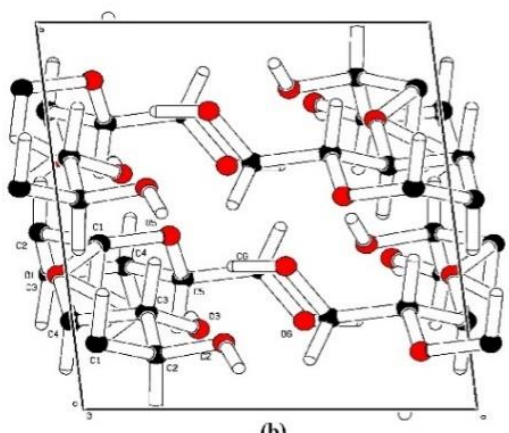

(b)

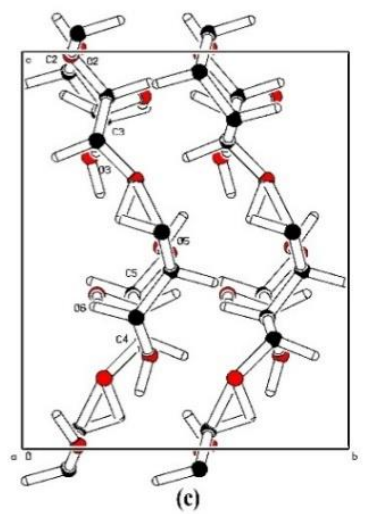

Fig. 3.The molecular structure of Suvin cotton fibre along with the spatial projections: (a) a-axis, (b) b-axis and (c) c-axis. 


\section{Suvin Cotton Fibre}

Table 2. The fractional atomic coordinates of Suvin cotton fibre after the refinement.

\begin{tabular}{cccc}
\hline Atom & $\mathrm{X}$ & $\mathrm{Y}$ & $\mathrm{Z}$ \\
\hline O1 & -0.02167 & 0.34726 & 0.67763 \\
O2 & 0.37752 & 0.17129 & 1.00800 \\
O3 & 0.31764 & 0.20770 & 0.73505 \\
O5 & -0.12494 & 0.14985 & 0.99206 \\
O6 & -0.44145 & 0.36986 & 0.88713 \\
C1 & 0.09265 & 0.42737 & 0.5460 \\
C2 & 0.20264 & 0.14127 & 0.94853 \\
C3 & 0.19066 & 0.24966 & 0.83063 \\
C4 & -0.00251 & 0.22846 & 0.77551 \\
C5 & -0.14616 & 0.26089 & 0.88758 \\
C6 & -0.34543 & 0.23634 & 0.84781 \\
\hline
\end{tabular}

Table 3. Model parameters of Suvin cotton fibre after some refinements using intensities of X-ray diffraction data.

\begin{tabular}{|c|c|c|c|c|c|c|c|c|c|c|c|c|c|c|}
\hline \multirow[t]{2}{*}{ 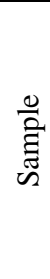 } & \multicolumn{3}{|c|}{ 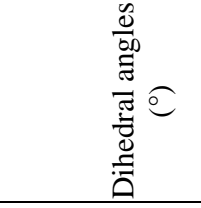 } & \multicolumn{4}{|c|}{ 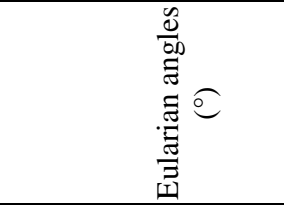 } & \multicolumn{4}{|c|}{ 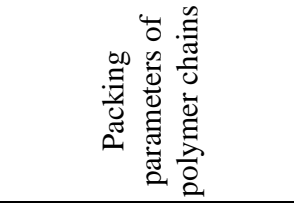 } & \multirow{2}{*}{ 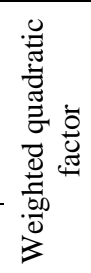 } & \multirow{2}{*}{ 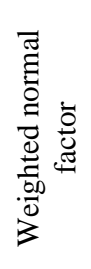 } & \multirow{2}{*}{ 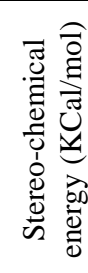 } \\
\hline & $\Phi$ & $\Psi$ & $X$ & $\mathrm{~T}$ & $\varepsilon_{x}$ & $\varepsilon_{y}$ & $\varepsilon_{Z}$ & $\mu_{1}$ & $w_{1}$ & $\mu_{2}$ & $w_{2}$ & & & \\
\hline 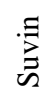 & $\begin{array}{l}\infty \\
\infty \\
\infty\end{array}$ & $\stackrel{i}{\stackrel{2}{n}}$ & $\begin{array}{l}\vec{m} \\
\stackrel{0}{0} \\
\stackrel{1}{1}\end{array}$ & $\begin{array}{l}\overrightarrow{0} \\
\dot{0} \\
\dot{D}\end{array}$ & $\begin{array}{l}\infty \\
\text { m. } \\
\stackrel{\delta}{0}\end{array}$ & $\frac{\infty}{i}$ & 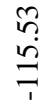 & $\Xi$ & ô. & $\begin{array}{l}\text { ले } \\
\infty \\
0 \\
0\end{array}$ & $\begin{array}{l}\text { o } \\
\text { ñ }\end{array}$ & $\begin{array}{l}\hat{n} \\
\tilde{n}\end{array}$ & $\begin{array}{l}\stackrel{\Omega}{\Omega}\end{array}$ & $\begin{array}{l}8 \\
\stackrel{8}{\infty} \\
\text { N }\end{array}$ \\
\hline
\end{tabular}

\subsection{Elastic stiffness coefficient}

The dependence of the elastic properties of an anisotropic body on the direction in a threedimensional space can be calculated directly using the components of the elasticity tensor $\left|\mathrm{C}_{\mathrm{ij}}\right|$. The mechanical properties reported in this were computed using Treloar [21] assumptions. $\left|\mathrm{C}_{\mathrm{ij}}\right|$ indicates $4^{\text {th }}$ rank elasticity tensor that has 21 [22] unique elastic constants depending on the symmetry of the system. Our sample has 13 elastic constants due to being monoclinic.

$$
\left[\begin{array}{cccccc}
\mathrm{C}_{11} & \mathrm{C}_{12} & \mathrm{C}_{13} & - & \mathrm{C}_{15} & - \\
\mathrm{C}_{21} & \mathrm{C}_{22} & \mathrm{C}_{23} & - & \mathrm{C}_{25} & - \\
\mathrm{C}_{31} & \mathrm{C}_{32} & \mathrm{C}_{33} & - & \mathrm{C}_{35} & - \\
- & - & - & \mathrm{C}_{44} & - & \mathrm{C}_{46} \\
\mathrm{C}_{51} & \mathrm{C}_{52} & \mathrm{C}_{53} & - & \mathrm{C}_{55} & - \\
- & - & - & \mathrm{C}_{64} & - & \mathrm{C}_{66}
\end{array}\right]
$$

Here, $\mathrm{C}_{11}, \mathrm{C}_{22}, \mathrm{C}_{33}$ are the stiffness constants along three principal axes a, b and c. $\mathrm{C}_{55}$, $\mathrm{C}_{66}$ are the stiffness constants against angular distortions under shear strain. The off- 
diagonal elements are corresponding to coupling effects. Anisotropic stiffness is subjected to uniaxial tensile deformation. The obtained stiffness matrix is shown in Table 4.

Table 4. Stiffness constants for Suvin cotton fibre.

\begin{tabular}{cc}
\hline Elastic constants & Suvin cotton fibre \\
\hline $\mathrm{C}_{11}$ & $3.83 \times 10^{10}$ \\
$\mathrm{C}_{22}$ & $3.79 \times 10^{11}$ \\
$\mathrm{C}_{33}$ & $7.76 \times 10^{10}$ \\
$\mathrm{C}_{12}$ & $-1.97 \times 10^{10}$ \\
$\mathrm{C}_{23}$ & $-3.25 \times 10^{10}$ \\
$\mathrm{C}_{44}$ & $5.40 \times 10^{10}$ \\
$\mathrm{C}_{55}$ & $2.10 \times 10^{10}$ \\
$\mathrm{C}_{66}$ & $3.06 \times 10^{10}$ \\
\hline
\end{tabular}

\section{Results and Discussion}

The elastic stiffness constants define macroscopically measurable quantities which is vital to know the elastic and mechanical properties of considered cotton fibre. Employing Linked Atom Least Square (LALS) method, the crystal structure of our sample has been computed and shown in Fig. 3 for Suvin cotton fibre. The stereo-chemical energy has been computed, which gives information about the energy required for the formation of the fibre. The energy decreases or increases depending on the polymer network embedded in an amorphous base of the fibre. After evaluating the elastic constant matrix, the moduli such as Young's modulus $(E)$, Shear modulus $(G)$, Bulk modulus $(B)$, Poisson's ratio $(v)$ and linear compressibility $(\beta)$ have been calculated using Voigt theory [23]. To carry out the mechanical property calculations $6 \times 6$ stiffness matrix tensors of $2^{\text {nd }}$ order elastic constants $\left|\mathrm{C}_{\mathrm{ij}}\right|$ is considered in Voigt symbolization [24]. These are calculated by performing small perturbance along each of 6 deformation modes, then analyse it further with tensor analysis tools such as the ELATE web application tool [25]. This tool gives the information about the volumetric and anisotropic property of a material such as Bulk modulus, direction dependent Young's modulus, Linear compressibility's, Shear modulus, and Poisson's ratio. In these calculations the computation time depending on many parameters such as system size, the deformation mode quantity, the point group symmetries enduring after specific deformations, and the number of steps required for convergence. These steps can be decreased by decreasing the deformation amplitude.

\subsection{Young's modulus (E)}

It is the ratio of uniaxial stress to the uniaxial strain along a unit vector $u$ [22] and it is the directional dependent and expressed in Fig. 4 for Suvin cotton fibre, where the surface compares to the spherical plot of $E(u)$ acquired from the condition -

$$
E(u)=\frac{1}{u_{i} u_{j} u_{k} s_{i j k l}}
$$


The maximum and minimum value of Young's modulus represented in Table 5 and is due to the direction compression or tension. Fig. 4 clearly presents the three-dimensional space, illustrating the dependence $E(u)$ in spherical coordinates. The directions of $E_{\min }$ correspond to the maximum values of the shear modulus $G_{\max }$ and vice versa [26].
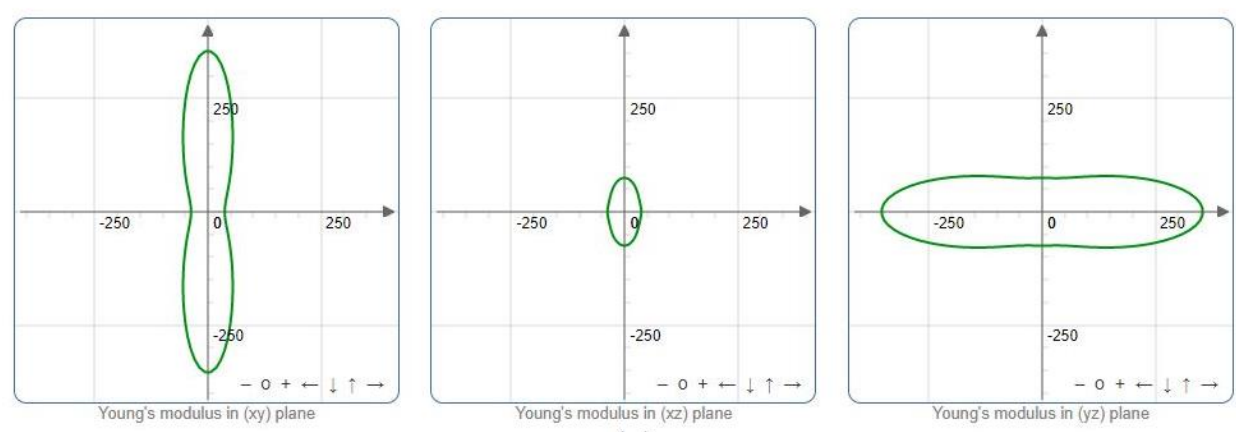

(a)

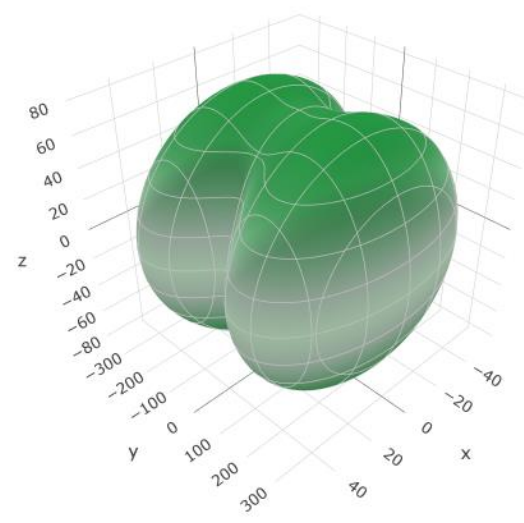

(b)

Fig. 4. Young's modulus representation surfaces E(u) (a) Spatial dependence and (b) Surfaces of the largest and smallest possible values of the Young's modulus.

Table 5.Mechanical properties of Suvin cotton fibre.

\begin{tabular}{cccccccc}
\hline \multicolumn{2}{c}{$\begin{array}{c}\text { Young's modulus } \\
(\mathrm{GPa})\end{array}$} & \multicolumn{2}{c}{$\begin{array}{c}\text { Linear compressibility } \\
\mathrm{TPa}^{-1}\end{array}$} & \multicolumn{2}{c}{$\begin{array}{c}\text { Shear modulus } \\
(\mathrm{GPa})\end{array}$} & \multicolumn{2}{c}{ Poisson's ratio } \\
\hline $\mathrm{E}_{\min }$ & $\mathrm{E}_{\max }$ & $\beta_{\min }$ & $\beta_{\max }$ & $\mathrm{G}_{\min }$ & $\mathrm{Gmax}$ & $v_{\min }$ & $v_{\max }$ \\
37.23 & 355.26 & 5.44 & 28.90 & 21 & 72.26 & -0.51 & 0.07 \\
\hline
\end{tabular}

\subsection{Rigidity modulus $(G)$}

The rigidity or shear modulus can be shown in 3-dimensional depiction, but depending on the additional unit vector $\mathbf{v}$, and it is perpendicular to the vector $u$. The surface of the 
spherical plot is as shown in Fig. 5, the maximum and minimum value of $G(\mathrm{u}, \mathrm{v})$ computed from as proposed by Ryder et al. [22] -

$$
G(u, v)=\frac{1}{u_{i} v_{j} u_{k} u_{l} s_{i j k l}}
$$
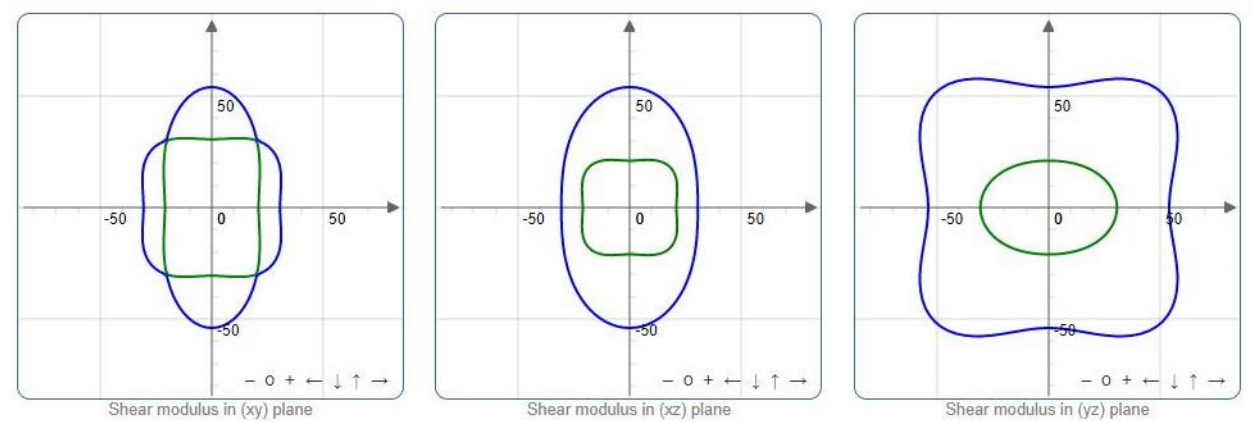

(a)

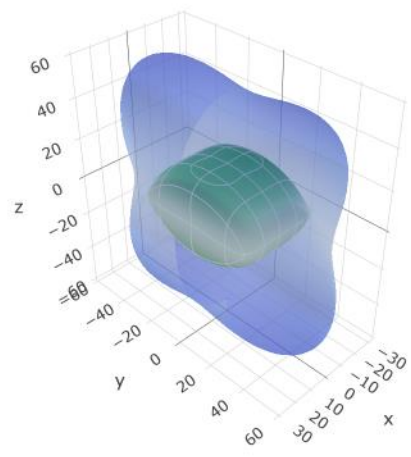

(b)

Fig. 5. Shear modulus representation surfaces G(u.v) (a) Spatial dependence and (b) Surfaces of the largest and smallest possible values of the Shear modulus.

\subsection{Poisson's ratio (v)}

It is also corresponding to shear modulus and it is a function of two-unit vectors, which is shown in Fig. 6. In this figure, the positive and negative values are represented by blue and red colour for the minimum and maximum values of Poisson's ratio. It is the ratio of transverse strain to the axial strain under uniaxial deformation and it is given by Ryder et al. [22]-

$$
v(u, v)=-\frac{u_{i} u_{j} v_{k} s_{i j k l}}{u_{i} u_{j} u_{k} u_{l} s_{i j k l}}
$$



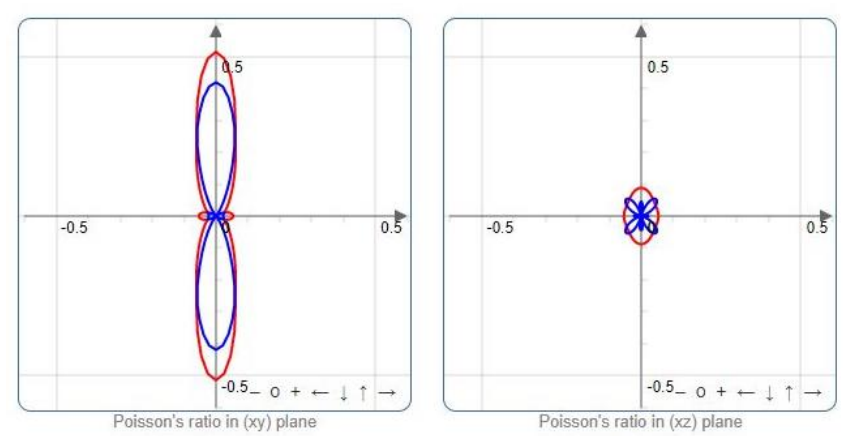

(a)

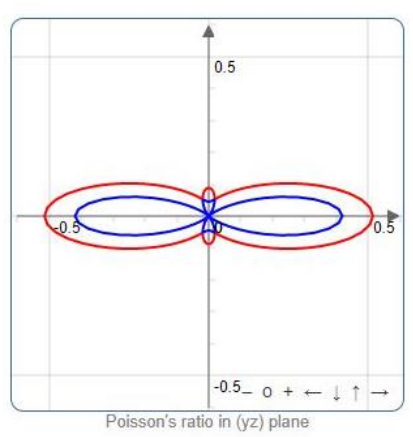

Poisson's ratio in (yz) plane

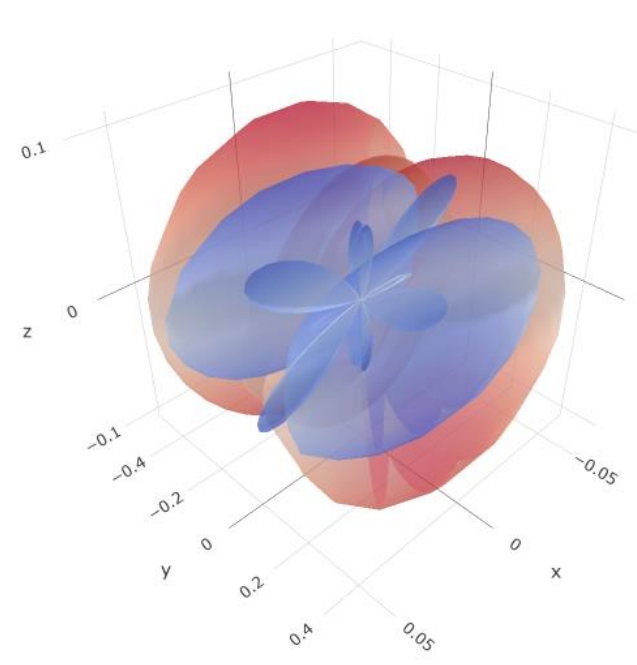

(b)

Fig. 6. Poisson's ratio representation surfaces $v(u, v)$ (a) Spatial dependence and (b) Surfaces of the largest and smallest possible values of the Poisson's ratio.

The material which has negative or zero Poisson's ratio has got an enormous application in the industries. In our study, the Suvin cotton fibre exhibits significant negative Poisson's proportion along with spatial direction and belongs to low symmetry space group of the monoclinic system. The negative Poisson's ratio is due to the auxetic effect in cotton. Due to this effect, when cotton is stretched, they become thicker perpendicular to the applied force. This occurs due to their particular internal structure and the way this deforms when the sample is uniaxially loaded [23]. In order to determine the Poisson's ratio in the spherical coordinates, it requires an extra dimension along with, $\theta$ $(0, \pi)$ and $\varphi(0,2 \pi)$ coordinates, i.e., $v(\theta, \varphi, \chi)$ [28]. The additional dimension can be characterized by an angle $\chi(0,2 \pi)$. In Fig. 6 , the surface which is obtained at the maximum value of $\chi$ is mentioned in blue colour and the red lobe indicates the positive (negative) values of the surface obtained for the minimum value of $\chi$ [28]. 


\subsection{Linear compressibility $(\beta)$}

The linear compressibility is positive for the majority of materials. The anisotropic linear compressibility $\beta(u)$ is the compression along an axis upon isostatic compression and can be obtained as proposed by Ryder et al. [22] -

$$
\beta(u)=u_{i} u_{j} s_{i j k l}
$$

The 3-dimensional representation of anisotropic surface is as shown in Fig. 7. There are materials with negative linear compressibility (NLC), the structure expands in one direction under isostatic pressure, while its total volume decreases.

The bulk modulus of material provides resistance to hydrostatic firmness and the values are computed using Voigt theory. The Voigt assumes a uniform strain.
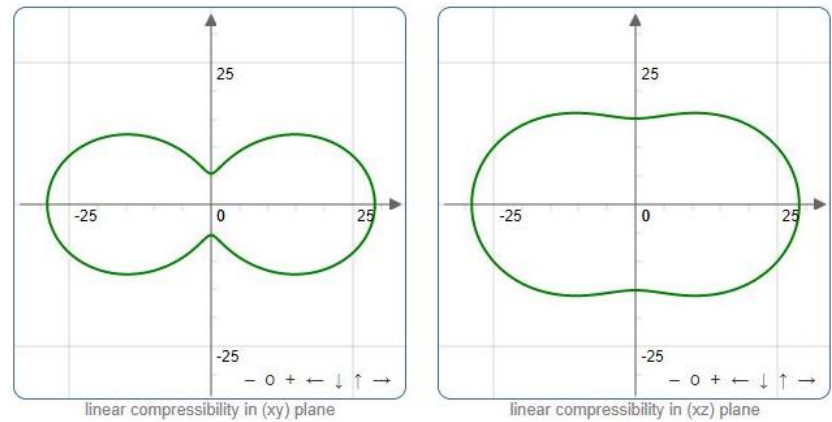

(a)

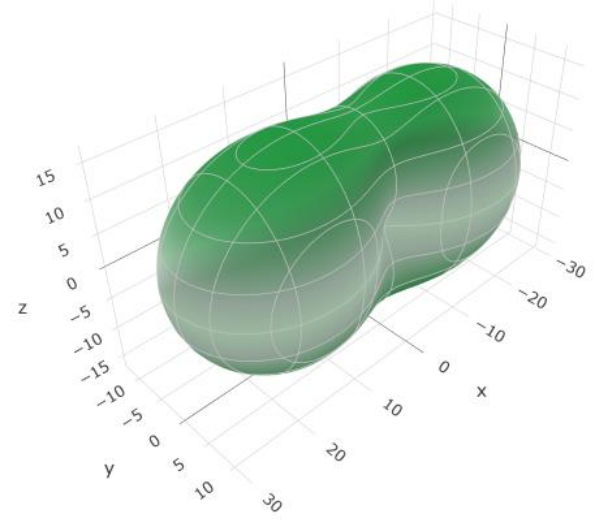

(b)

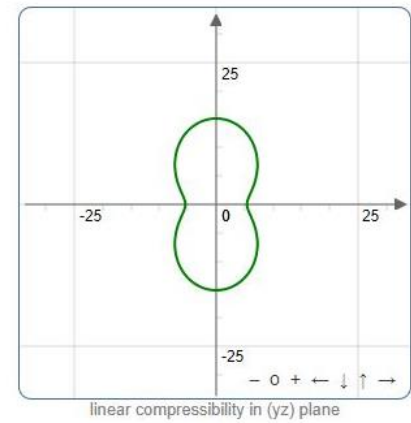


spherical one, this indicates a strong anisotropic of the elastic properties. The experimental and theoretical values of different elastic moduli are tabulated in Table 6.

Table 6. Elastic moduli for Suvin cotton fibre.

\begin{tabular}{|c|c|c|c|c|c|c|c|c|}
\hline \multirow[b]{2}{*}{ 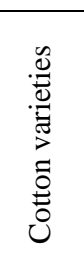 } & \multirow[b]{2}{*}{ 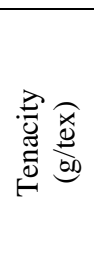 } & \multirow[b]{2}{*}{ 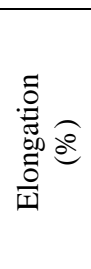 } & \multicolumn{2}{|c|}{$\begin{array}{c}\text { Young's modulus (E) } \\
(\mathrm{GPa})\end{array}$} & \multicolumn{2}{|c|}{$\begin{array}{l}\text { Bulk modulus (K) } \\
(\mathrm{GPa})\end{array}$} & \multicolumn{2}{|c|}{$\begin{array}{c}\text { Shear modulus }(\mathrm{G}) \\
(\mathrm{GPa})\end{array}$} \\
\hline & & & 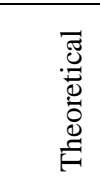 & 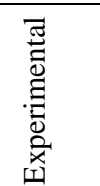 & 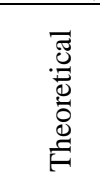 & 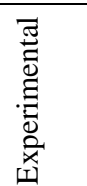 & 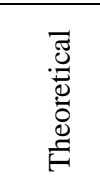 & 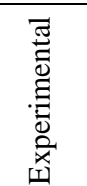 \\
\hline Suvin & 20.1 & 13.2 & 120 & 123 & 43.38 & 82 & 57.59 & 49.2 \\
\hline
\end{tabular}

Using the experimentally obtained values of tenacity and elongation the elastic moduli has been computed [29],

$$
\text { Young's modulus }(E)=\frac{\gamma_{1}}{\epsilon_{1}}
$$

where $\gamma_{1}$ is the tenacity (g/tex), $\epsilon_{1}$ is the elongation (\%).

$$
\begin{aligned}
& \text { Shear modulus }(G)=\frac{E}{2(1+v)} \\
& \text { Bulk modulus }(K)=\frac{E}{3(1-2 v)}
\end{aligned}
$$

where $v$ is the Poisson's ratio and its limiting value is 0 to 0.5 , for cotton fibre it is taken as 0.25 [30]. In order to convert the unit of modulus from g/tex to GPa the following relation has been used,

$$
\text { Modulus }(\mathrm{GPa})=\frac{\mathrm{N} / \mathrm{tex}}{\operatorname{density~}\left(\mathrm{g} / \mathrm{cm}^{3}\right)}
$$

where,

$$
\mathrm{N} / \text { tex }=11.3 \times \frac{\mathrm{g} / \mathrm{tex}}{9}
$$

For the theoretical calculation of elastic modulus, the Voigt approximation is employed and there is a broad correlation between the theoretical and experimental results. The variation in Young's modulus, Bulk modulus, and Shear modulus for the considered cotton is because of the voids in the fibres which have not been taken in the estimation of elastic constants.

\subsection{Negative poisson's ratio}

Auxetic materials are those which have negative Poisson's ratio, those materials have got enormous applications in sensing technologies [31]. The ratio of lateral strain to longitudinal strain yields the Poisson's ratio under the stretching process. So, the auxetic materials stretches in the oblique direction when it is stretched in the longitudinal direction. It is observed that, the considered fibre shows significant negative Poisson's 
ratio along different spatial axes, which belongs to monoclinic and low symmetry. Hence, these inbuilt structures have got more advantages in technological applications. The minimum value of Poisson's ratio is -0.51 which is equivalent to the reported value for polymers -0.8 by Lake's et al. [32].

\section{Conclusion}

In this paper, WAXS data has recorded for Suvin cotton fibre. This data used to compute the microstructural and the unit cell parameters. From these investigations, the following observations have been made:

1. The crystal and molecular structure have been identified using the technique LALS and PLATON® programs for the considered cotton fibre. This is built using the model where two chains in a unit cell are corresponding with similar conformations.

2. Elastic moduli are determined from $6 \times 6$ elastic moduli tensor matrix and by using the ELATE web application tool, the variations of different moduli are plotted. It is observed that the 3-dimensional shapes strongly deviate from the spherical one, this indicates a strong anisotropic of the elastic properties.

3. The direction corresponding to maximum Young's modulus was correlated with the directions along which the Shear modulus is minimum. The Young's modulus and Shear modulus preserve the information about the anisotropy and their relationship to each other.

4. There is a broad correlation between the theoretical values of elastic moduli with experimental results.

\section{References}

1. O. M. Samir and R. Somashekar, Bull. Mater. Sci. 30, 503 (2007).

https://doi.org/10.1007/s12034-007-0079-5

2. S. J. Kim, J. B. Moon, G. H. Kim, and C. S. Ha Sam-Jung, Polym. Testing. 27, 801 (2008). https://doi.org/10.1016/j.polymertesting.2008.06.002

3. S. P. Bhatawdekar, S. Sreenivasan, R. H. Balasubramanya, and V. Sundaram, J. Appl. Polym. Sci. 44, 243 (1992). https://doi.org/10.1002/app.1992.070440208

4. M. Abdelmouleh, S. Boufi, A. Ben Salah, M. N. Belgacem, and A. Gandini, Langmuir 18, 3203 (2002). https://doi.org/10.1021/la011657g

5. V. A. Krakhmalev and A. A. Paiziev, Cellulose 13, 45 (2006). https://doi.org/10.1007/s10570-005-9023-2

6. P. Duan, Q. Xu, S. Shen, Y. Zhang, L. Zhang, F. Fu, and X. Liu, Fibres Polym. 20, 1803 (2019). https://doi.org/10.1007/s12221-019-9224-1

7. S. Thota, V. Somisetti, S. Kulkarni, J. Kumar, R. Nagarajan, and R. Mosurkal, Cellulose 27, 11 (2019). https://doi.org/10.1007/s10570-019-02801-6

8. Y. Bao, X. Li, P. Tang, C. Liu, W. Zhang, and J. Ma, Cellulose 26, 9311 (2019). https://doi.org/10.1007/s10570-019-02709-1

9. O. J. Otutu and A. K. Asiagwu, J. Sci. Res. 11, 215 (2019). https://doi.org/10.3329/jsr.v11i2.38734

10. D. S. Kumar, Kumari, and D. Verma. J. Sci. Res. 11, 235 (2019). http://dx.doi.org/10.3329/jsr.v11i2.39286

11. A. L. J. Spek, J. Appl. Crystallogr. 36, 7 (2003). https://doi.org/10.1107/S0021889802022112 
12. F. Tran-Van, S. Garreau, G. Louarn, G. Froyer, and C. Chevrot, J. Mater. Chem. 11, 1378 (2001). https://doi.org/10.1039/B100033K

13. K. Aasmundtveit, E. Samuelsen, L. Pettersson, O. Inganäs, T. Johansson, and R. Feidenhans, Synth. Met. 101, 561 (1999). https://doi.org/10.1016/S0379-6779(98)00315-4

14. V. V. Manju, S. Divakara, and R. Somashekhar, AIP Conf. Proc. 1832, 040013 (2017). https://doi.org/10.1063/1.4980215

15. B. D. Butler, D. R. Haeffner, P. L. Lee, and T. R. blberry, J. Appl. Crystallogr. 33, 1046 (2000). https://doi.org/10.1107/S0021889800005318

16. R. Chen, K. A. Jakes, and D. W. Foreman, J. Appl. Polym. Sci. 93, 2019 (2004). https://doi.org/10.1002/app.20666

17. K. Namratha, S. Suresha, M. B. Nayan, and K. Byrappa, Res. Chem. Intermediat. 37, 531 (2011). https://doi.org/10.1007/s11164-011-0282-2

18. A. U. Nair, R. P. Nachane, and B. A. Patwardhan, Ind. J. Fibre Text 34, 352 (2009).

19. ISI Handbook of Textile Testing, IS 3675-1966 (Bureau of Indian Standards, New Delhi, 1982). URL:https://law.resource.org/pub/in/bis/S12/is.sp.15.1.1989.pdf

20. P. J. Smith, Campbell, and S. Arnott, Acta Cryst. B 34, 3 (1978). https://doi.org/10.1107/S0567739478000029.

21. L. G. Treloar, Polymer 1, 95 (1960). https://doi.org/10.1016/0032-3861(60)90012-4

22. M. R. Ryder, and J. -C. Tan, Dalton Trans. 45, 4154 (2016). https://doi.org/10.1039/C5DT03514G

23. Z. Penava, D. ŠimićPenava, and Z. Knezić, Tehničkiglasnik 11, 101 (2017). URL:https://hrcak.srce.hr/index.php?show=clanak\&id_clanak_jezik=275275

24. R. Agbaoye, P. Adebambo, J. Akinlami, T. Afolabi, S. Z. Karazhanov, D. Ceresoli, and G. Adebayo, Comput. Mater. Sci. 139, 234 (2017). https://doi.org/10.1016/j.commatsci.2017.07.042

25. C. S. Man and M. Huang, J. Elast. 105, 29 (2011). https://doi.org/10.1007/s10659-011-9312-y

26. R. Gaillac, P. Pullumbi, and F. X. Coudert, J. Condens. Matter Phys. 28, 275201 (2016). https://doi.org/10.1088/0953-8984/28/27/275201

27. V. A. Saleev and A. V. Shipilova, Russ. J. Phys. Chem. B 92, 1940 (2018). https://doi.org/10.1134/S003602441810028X

28. O. Pavlic, W. Ibarra-Hernandez, I. Valencia-Jaime, S. Singh, G. Avendaño-Franco, D. Raabe, and A. H. Romero, J. Alloys Compd. 691, 15 (2017). https://doi.org/10.1016/j.jallcom.2016.08.217

29. By-Products of Palm Trees and Their Applications (Materials Research Forum LLC, 2019). https://doi.org/10.21741/9781644900178-22

30. R. Meredith, J. Text. Inst. 37, T205 (1946). https://doi.org/10.1080/19447024608659812

31. S. Singh, I. Valencia-Jaime, O. Pavlic, and A. H. Romero, Phys. Rev. B 97, 054108 (2018). https://doi.org/10.1103/PhysRevB.97.054108

32. R. Lakes, Science 238, 551 (1987). https://doi.org/10.1126/science.238.4826.551-a 